\title{
From four hands to two feet: human evolution in the context of primate evolution
}

\author{
Tetsuro Matsuzawa ${ }^{1,2}$
}

Published online: 9 March 2016

(C) Japan Monkey Centre and Springer Japan 2016

There is a commonly held naïve belief regarding human evolution: that quadrupedal animals began to stand up, liberating two of their limbs from the task of locomotion, thus creating two hands for manipulating objects, resulting eventually in skilled tool use and cerebral enlargement. This is incorrect in terms of primate evolution. The correct interpretation is as follows. The common ancestors of all mammals today were small terrestrial mammals with four legs. The shared ancestor of primates moved into the treetops and developed four hands from the four feet possessed by the terrestrial ancestor. This was an adaptation to arboreal life; enabling the efficient grasping of branches and tree-trunks. Subsequently, early human ancestors left the trees to start walking long distances across the land, bipedally. Thus, we created two feet from four hands during the course of evolution from our early primate ancestor.

Gen Suwa of the University of Tokyo and his colleagues recently reported the discovery of a fossil record of the ancestral type of gorillas (Katoh et al. 2016). They used various methods to determine the geological age of the fossil and reported that it is about 8 million years old. This allowed them to estimate that the split between the gorilla and human-chimpanzee lineage likely occurred around 10 million years ago; this is earlier than previously thought. Let us consider human evolution by looking at what we mean by a "foot" and a "hand".

Ardipithecus ramidus fossils (White et al. 2009), found in the Afar Rift, Ethiopia, were formed 4.4 million years

Tetsuro Matsuzawa

matsuzawa.tetsuro.8w@kyoto-u.ac.jp

1 Primate Research Institute, Kyoto University, Inuyama, Japan

2 Japan Monkey Centre, Inuyama, Japan ago. The most spectacular group of specimens represents part of one complete skeleton. These finds helped clarify the evolution of early hominids, with implications for understanding the evolution of today's African apes. The feet of A. ramidus suggest this species climbed trees somewhat like chimpanzees, but not entirely. Individuals apparently used the whole flat of their foot when traversing vegetation, and, when necessary, climbed cautiously using a manner of bipedal locomotion that represented a precursor to the full terrestriality of Australopithecus.

Between 2 and 4 million years ago, Australopithcus spp., including affarensis and africanus, inhabited parts of East Africa. The Australopithecus affarensis specimen named Lucy constitutes about $40 \%$ of an entire female skeleton, but very little remains of the feet. Other fossil evidence, however, indicates that the species exhibited bipedal locomotion.

My focus is on the study of chimpanzees, both in the wild (Matsuzawa et al. 2011) and in the laboratory (Matsuzawa et al. 2006), with the aim to better understand what we share with chimpanzees and what is unique to humans. I was aware that chimpanzees have feet that resemble hands in appearance and shape (Fig. 1). I wished to visit paleoanthropological sites to enable me to picture the life led by the earliest human ancestors. In the summer of 2008, I was presented with the opportunity to visit such a site in Kenya, thanks to my ex-student Susana Carvalho, a doctoral graduate of the University of Cambridge and now an associate professor in palaeoanthropology at the University of Oxford, having contributed to founding the discipline of primate archaeology. We travelled together to view the digging survey being carried out by an international team at Ileret, Kenya, led by Jack Harris of Rutgers University.

The excavation site is on the East coast of Lake Turkana. The climate was very hot and dry during our visit. 


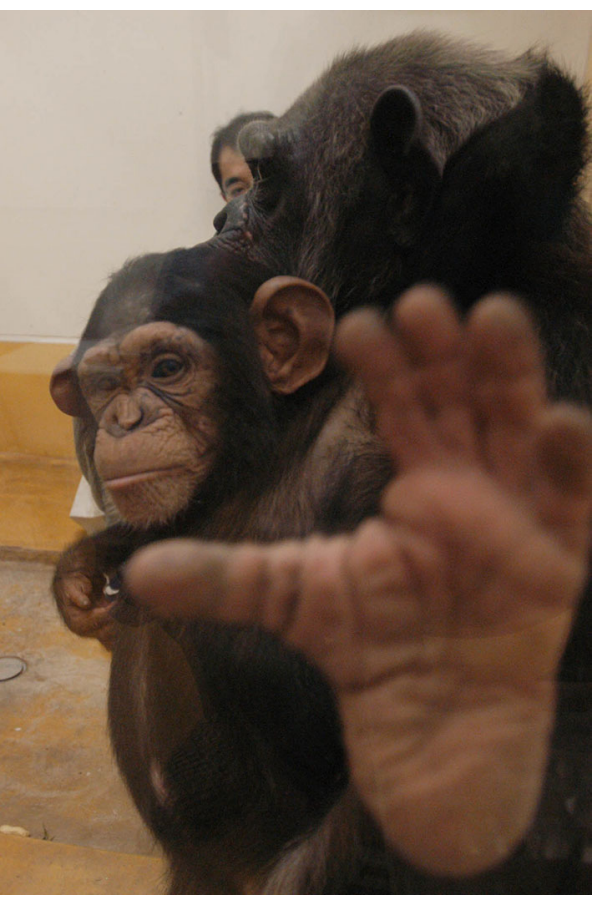

Fig. 1 Foot of a chimpanzee, Cleo, showing the similarities to human hands (photo: Tetsuro Matsuzawa)

Fossil skulls and bones of various species were scattered across the desiccated ground resembling a stereotypical desert. I found it most interesting to see that the fossilized elephant teeth more closely resembled those of Asian rather than African elephants. The international team was focusing on a geological layer formed 1.52 million years ago. There were footprints of various species preserved within this layer. I had the opportunity to compare my foot directly to a fossilized hominid footprint (Fig. 2). At a glance, they appear very similar in size and shape. The fossilized footprint shows us that the feet of this hominid

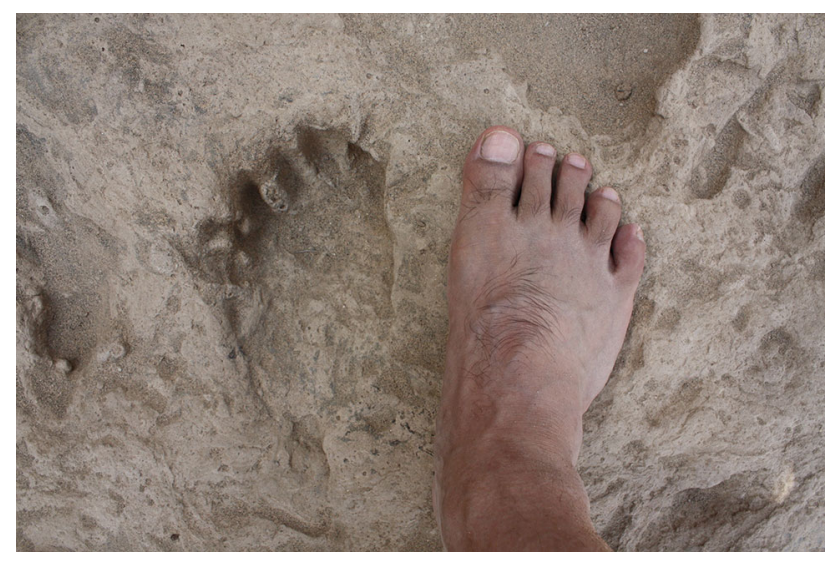

Fig. 2 Hominid footprint formed 1.5 million years ago, in Ileret, east coast of Lake Turkana, Kenya, pictured alongside the foot of the author (photo: Tetsuro Matsuzawa) were close to those of modern humans, and different from those of chimpanzees.

The international team (Bennett et al. 2009) used a special apparatus, using the reflection of laser beams, to precisely measure the depth of the footprint. Fossilized footprints can tell us not only about the shape of hominid feet, but also about the way in which they walked. The team found the oldest example of foot morphology broadly resembling our own. The scientists found that the footprints at Ileret matched what would be expected from height and weight estimates for Homo ergaster/erectus, and were different in shape to footprints made by Australopithecus at Laetoli, Tanzania. The Ileret footprints indicate that the foot morphology had already evolved away from that of the common primate ancestor, with a larger range of movement and an opposable big toe, towards a form better suited to more efficient pushing off when walking along the ground, with the big toe parallel to the other toes and the foot arched. This suggests that by about 1.5 million years ago, our ancestors were already walking very much as we do today. As you may know, in contrast to the arched foot of humans, in chimpanzees and gorillas the sole is flat.

Allow me to summarize human evolution in the context of primate evolution from the mammalian ancestor. The Cenozoic era began around 66 million years ago. Most of the dinosaurs had gone and mammalian species radiated to fill available ecological niches. Some took to the sky, evolving into bats; forelegs becoming wing-like structures. Some dove into the sea, developing into dolphins and whales; limbs turning into to fin-shaped structures. Many continued to inhabit the ground as four-legged animals. Some ascended to the trees to become the common ancestor of primates; feet modified into hands. Four-legged animals became 'four-handed' animals in early primate evolution. Human ancestors left the trees and started invading the savanna. Upright posture and bipedal locomotion was more efficient for walking long distances. Thus, we might encapsulate the evolution of human bipedality in the context of primate evolution thus: from four hands to two feet.

\section{References}

Bennett MR, Harris JWK, Richmond BG, Braun DR, Mbua E, Kiura P, Olago D, Kibunjia M, Omuombo C, Behrensmeyer AK, Huddart D, Gonzalez S (2009) Early hominin foot morphology based on 1.5-million-year-old footprints from Ileret Kenya. Science 323(5918):1197-1201. doi:10.1126/ science. 1168132

Katoh S, Beyene Y, Itaya T, Hyodo H, Hyodo M, Yagi K, Gouzu C, WoldeGabriel G, Hart WK, Ambrose SH, Nakaya H, Bernor RL, Boisserie JR, Bibi F, Saegusa H, Sasaki T, Sano K, Asfaw B, Suwa G (2016) New geological and palaeontological age 
constraint for the gorilla-human lineage split. Nature 530:215-218. doi:10.1038/nature 16510

Matsuzawa T, Tomonaga M, Tanaka M (2006) Cognitive development in chimpanzees. Springer

Matsuzawa T, Humle T, Sugiyama Y (2011) Chimpanzees in Bossou and Nimba. Springer
White TD, Asfaw B, Beyene Y, Haile-Selassie Y, Lovejoy O, Suwa G, WoldeGabriel G (2009) Ardipithecus ramidus and the paleobiology of early hominids. Science 326(5949):64-86. doi:10.1126/science. 1175802 